\title{
Pilot Studies and Assessment of Downstream Effects of UV and Ozone Disinfection of a Physicochemical Wastewater
}

\author{
R. Geitr and J. Nicell
}

Depariment of Civil Engineering and Applied Mechanics, MCGill University, 877 Sherbrooke Street West, Montreal, Ouebec $\mathrm{H} 3 \mathrm{~A} 2 \mathrm{KG}$

\begin{abstract}
UV radiation and ozonation were investigated as disinfection alternatives for the Montreal Urban Community physicochemical wastewater treatment plant. The final effluent flows through a 5-km-long outfall tunnel before discharge into the St Lawrence River; the critical point for microbial quality is $4 \mathrm{~km}$ downstream. The study, therefore, also examined possible biofilm growth in the tunnel and dilution behaviour in the river. For UV disinfection, a newly developed, high-intensity medium-pressure lamp unit was tested because of its space-saving features. Typical two-stage dose-response curves were obtained with the transition between disinfection of free-swimming and particulateassociated organisms occurring at approximately $25 \mathrm{~mW} \cdot \mathrm{s} / \mathrm{cm}^{2}$. Disinfection behaviour improved when alum was substituted for $\mathrm{FeCl}_{3}$ as the coagulant. Photoreactivation decreased with increasing UV dose. Ozonation was adversely effected by changes in COD and $\mathrm{H}_{2} \mathrm{~S}$ in the wastewater. A dose of $17 \mathrm{mg} / \mathrm{L}$ was needed to reach target disinfection levels of $<5,000 \mathrm{CFU} / 100 \mathrm{~mL}$ in $90 \%$ of the cases; the CT value was approximately $0.4 \mathrm{mg} \cdot \mathrm{min} / \mathrm{L}$. Replacement of $\mathrm{FeCl}_{3}$ by alum reduced the required dose by $35 \%$. Effects of biofilm growth in the tunnel were inconsistent: effluent SS and microbial concentrations were sometimes higher at the exit than at the entrance, and vice versa. Effective dilution of microbes in the river decreased as water temperature increased, reaching a minimum of approximately 20.
\end{abstract}

Key words: UV disinfection, ozonation, physicochemical wastewater, biofilm

\section{Introduction}

In considering the type and level of disinfection to be applied to its treated effluent, the Montreal Urban Community wastewater treatment plant (MUCWTP) was faced with the classical dilemma of discharging an effluent which simultaneously met the required standards for microbiological and chemical quality. As described below, these restrictions necessitated investigating the use of UV or ozone as alternatives to chlorine disinfection. Since the plant employs only physicochemical processes upstream of disinfection, few, if any, similar existing plants could be relied upon to provide design data; hence, pilot studies for both processes were performed. The MUCWTP discharges its effluent via a $5-\mathrm{km}-\mathrm{long}$, belowgrade, outfall tunnel to the St Lawrence River. The critical point for 
microbial quality is $4 \mathrm{~km}$ downstream. Therefore, the potential for biofim growth in the tunnel, leading to increased microbial counts in the discharged effluent, as well as river effects such as dilution, photoreactivation, and other regrowth/dieoff phenomena, were also of concern. This paper describes these pilot plant studies, investigations into possible outfall biofilm and river effects, and the implications which each process would have on the overall management of effluent quality.

\section{Background}

\section{Approach Taken by the Quebec Government}

In 1986, the U.S. EPA, having surveyed 6,300 municipal wastewater treatment plants in the United States that chlorinate, expressed concern about the acute toxicity of chlorine residuals to aquatic life, as well as the long-term effects of disinfection by-products and/or dechlorination (EPA 1991). In response to these concerns, the Quebec Ministry of the Environment and Fauna (MEF) decided not to put into operation any chlorine facilities for wastewater disinfection and, in fact, requested the MUC not to start its newly completed chlorination facilities (Hamel 1993). A tentative limit has been set for fecal coliform (FC) discharges of 5,000 CFU / 100 $\mathrm{mL}$ during the summer months (Payette 1992). This value would be the monthly geometric mean of all daily samples taken during dry weather flow. It is based on the MEF requirement of $200 \mathrm{CFU} / 100 \mathrm{~mL}$ for swimming at a location $4 \mathrm{~km}$ downstream, taking into account dilution by the river (in this case, 25 times) but not reactivation of microorganisms. In an assessment published in 1990 of the St-Lawrence River as a drinking water source (for example, by communities downstream of Montreal), trihalomethanes and chloro-organic levels were noted to be of concern (Levallois 1990). Therefore, pilot studies were initiated to investigate UV radiation or ozone as alternative methods of wastewater disinfection

\section{Ultraviolet Radiation}

UV disinfects primarily by damaging the ability of nucleic acids to replicate. The nucleotide bases, which are the major UV-absorbing species, are similar in most respects from one organism to another (Cairns 1993). Hence the susceptibility of most organisms to UV disinfection is similar and is affected only by UV-absorbing compounds within the cell, such as proteins, and the physical size of the organism. The ratio of doses for inactivation of the most resistant bacterial spores and viruses, compared to $E$. coli, is only about 3.5-6 times, whereas the equivalent range for chlorine is as much as 100 times (Cairns 1993; EPA 1986). On the other hand, the inactivation of larger protozoan organisms, such as Giardia lamblia and Cryptosporidium spp. will require excessive doses of either chlorine or UV, and should preferably be removed by filtration.

Photochemistry is relatively independent of $\mathrm{pH}$, temperature, pres- 
ence of ammonia and ionic strength, all of which influence chlorination profoundly. On the other hand, the presence of particulates exhibits a major shielding effect during chlorination and especially during UV disinfection (Darby et al. 1993). The effect of turbidity on chlorination disinfection efficiency has been well documented, and in one case, when particles were disrupted following passage of the sample through the sampling pump, the bacterial count increased over 100 times (White 1986). The ultimate goal (usually the desired effluent count) will strongly influence selection of the required UV dose, especially if the desired count is below that due to particulate-associated microbes. For a tertiary filter effluent (effluent turbidity less than 2 NTU), a UV dose of $100 \mathrm{~mW} \cdot \mathrm{s} / \mathrm{cm}^{2}$ was needed to reduce total coliform concentrations to the California standard of 2.2 most probable number (MPN)/100 mL or less, and 140 $\mathrm{mW} \cdot \mathrm{s} / \mathrm{cm}^{2}$ was needed to achieve a 4-log inactivation of vaccine polio viruses and coliphages F2 and MS2 (Chen et al. 1993). This is in contrast to more typical doses of $30-50 \mathrm{~mW} \cdot \mathrm{s} / \mathrm{cm}^{2}$, or even less, if the 100 to 200 colony-forming units (CFU)/100 mL levels are desired.

Recovery from disinfection is a phenomenon exhibited by UV disinfection (EPA 1986). A dark repair mechanism, called excision repair, applies to both photo-damaged and chemically damaged organisms; however this mechanism involves a multi-enzyme process which requires nutrients. Photoreactivation, on the other hand, is limited to the reversal of UVinduced pyrimidine dimerization within the nucleic acids and requires only light energy, not chemical nutrients. Viruses and some bacteria do not have the enzymes to photoreactivate, and the mechanism is obviously confined to the surface layers of open channels and rivers. Bacteria in particles will also not be much affected by photoreactivation. Although it has been suggested that the extent of photoreactivation is independent of the original inactivating dose (EPA 1986; Whitby and Palmateer 1993), other studies have shown that the extent of photoreactivation is inversely related to the original UV dose (Lindenauer and Darby 1993).

In contrast to both chlorination and ozonation, toxic or mutagenic by-products in wastewaters and drinking waters have not been found as a result of UV radiation. However, it has been suggested that an inhibitory effect on biofilm formation following UV irradiation could be due to the presence of residual hydrogen peroxide and/or oxygen radicals resulting from irradiation of the humic substances (Lund and Ormerod 1995).

\section{Ozone}

Ozone is a popular disinfectant for potable waters as well as for a variety of industrial wastewaters, but it has so far had little application as a wastewater disinfectant. Ozone can oxidize disinfectant by-product (DBP) precursors, but it also produces its own DBPs such as aldehydes, ketones and carboxylic acids, and it increases the availability of bacterial nutrients by converting nonbiodegradable organic matter to biodegradable compounds (Miltner et al. 1992; Jacangelo et al. 1989). An implication of this could be bacterial regrowth in the outfall system. 
Reactivation of microorganisms exposed to ozonation could occur in a manner similar to dark repair of UV inactivated organisms (EPA 1986), but it has not been widely observed.

\section{Montreal Urban Community Wastewater Treatment Plant}

The Montreal Urban Community wastewater treatment plant (MUCWTP) is a physicochemical plant, which treated an average flow of $15 \mathrm{~m}^{3} / \mathrm{s}$ (maximum $45 \mathrm{~m}^{3} / \mathrm{s}$ ) mainly from the North interceptor of the Island of Montreal at the time of the study. The South interceptor was still under construction, and functioned intermittently, hence the septic conditions which developed were responsible for occasional significant $\mathrm{H}_{2} \mathrm{~S}$ concentrations in the wastewater.

The processes at the MUCWTP include screening, grit removal and sedimentation enhanced by chemical addition $\left(\mathrm{FeCl}_{3} @ 6-20 \mathrm{mg} \mathrm{Fe}^{3+} / \mathrm{L}\right.$ and anionic polyelectrolyte [Percol 902, Allied Colloids] @ 0.2-0.3 mg/L). Discharge, via a $5-\mathrm{km}$-long, below-grade outfall tunnel $\left(\sim 2 \frac{1}{2}\right.$ hours retention time at average flow) is into the St Lawrence River, which flows in an easterly direction at approximately $9,000 \mathrm{~m}^{3} / \mathrm{s}$. The MUCWTP is actually equipped with a chlorination system but it is not operational due to the abovementioned environmental concerns. Thus UV or ozone disinfection would appear to be appropriate disinfection alternatives. Furthermore, ozone could be injected directly into the outfall tunnel, thus reducing the cost of the contacting infrastructure.

As mentioned above, ozonation can increase the biodegradability of organic materials, and hence the BOD (van Leeuwen 1987). Indeed, the BOD of the effluent following ozonation did increase, as reported below. This, in turn, could lead to additional biofilm growth in the long outfall tunnel, and hence an increase in microbial counts in the discharged effluent. This effect could not be studied directly on the full-scale outfall, but it was believed that biofilm growths might still occur under the existing conditions. Although the Reynolds' number in the tunnel exceeds $10^{6}$ at average flows, and this would appear to be too high for the development of a biofilm, there is a laminar sublayer, which at a flow of $18 \mathrm{~m}^{3} / \mathrm{s}$, would reach a thickness of between 0.34 and $0.41 \mathrm{~mm}$, depending on the roughness of the concrete surface (Gehr et al. 1994). A biofilm of such thickness could thus be expected (Bryers 1987; Picologlou et al. 1980).

\section{Objectives}

The objectives of this study were to investigate the performance and implications of UV or ozone disinfection of the effluent produced by the physicochemical process train at the MUCWTP. In addition to the basic performance characteristics of each process, two downstream phenomena could influence final bacterial counts, and these were also investigated. First, because of the unique nature of the outfall system, consisting of an underground pipe flowing under pressure with a relatively long retention 
time, the possibility existed of biofilm growth, especially with the increased BOD levels following ozonation. Second, the effective dilution potential of the St. Lawrence River was also assessed.

\section{Materials and Methods}

\section{UV Disinfection}

Due to the high flows experienced, medium-pressure UV lamps were considered to be the only practical choice. Many successful fullscale installations using low-pressure UV lamps have been documented (Maarschalkerweerd et al. 1990; White et al. 1986), but it is only recently that reliable medium-pressure lamp technology has become available for wastewater treatment (Gehr and Cairns 1994). These lamps can generate an average germicidal intensity of 10 times or more that of low-pressure lamps.

The pilot UV reactor contained two banks of four medium-pressure lamps, each $98.4 \mathrm{~W} / \mathrm{cm}$ and $30.5 \mathrm{~cm}$ long, in a $2 \times 2$ array @ $12.7 \mathrm{~cm}$ centre-centre spacing. Each lamp was protected by a $3.3-\mathrm{cm}$-diameter quartz sleeve. Treated effluent was pumped from the effluent channel by a submersible pump at metered flow rates of $750-9,400 \mathrm{~L} / \mathrm{min}$, corresponding to nominal detention times of less than $5 \mathrm{~s}$, and the disinfected flow was then returned to the same channel.

Before each set of experiments, the pump was run at its highest flow, or continuously, to flush out any biofilm or other contamination from the pilot plant. Experiments were generally performed between $10 \mathrm{~h} 00$ and $14 \mathrm{~h} 00$, but some tests were also done at $1 \mathrm{~h} 00$ when the effluent quality was poorest. All samples were grab samples. Analysis of the reported chemical parameters was performed on site within a few hours after sampling; samples for FC enumeration were stored on ice and tested within 24 hours of sampling.

Photoreactivation was evaluated by immersing disinfected wastewater samples contained in flat Pyrex glass bottles into the wastewater channel at various depths (maximum $2 \mathrm{~m}$ ) for up to 3 hours. Some bottles were covered to allow for dark repair only. In this way the overall environment (temperature and light absorption characteristics) of the outfall tunnel as well as the effluent plume in the river could be simulated. It was assumed that the light absorption characteristics of this effluent in the channel would be similar to that of the effluent plume in the river.

The average intensity in the reactor was calculated by the single point source summation (SPSS) method of Trojan Technologies Inc., which provided comparable results to the point source summation method (EPA 1986). UV dose is a function of the flow rate (hence, the detention time in the reactor) and the average light intensity (hence, the transmittance of the wastewater). For the photoreactivation experiments, typical values of "low", "medium" and "high" doses were 15 to 20 $\mathrm{mW} \cdot \mathrm{s} / \mathrm{cm}^{2}, 30$ to $40 \mathrm{~mW} \cdot \mathrm{s} / \mathrm{cm}^{2}$ and 80 to $90 \mathrm{~mW} \cdot \mathrm{s} / \mathrm{cm}^{2}$, respectively. 
UV disinfection performance was assessed in terms of inactivation of fecal coliforms. Other parameters measured included suspended solids (SS), turbidity, UV transmittance before and after filtration, iron, aluminium and DOC. The methodologies for all parameters were taken from Standard Methods (APHA et al. 1989), with the exception of UV transmittance, which used a spectrophotometer developed by Trojan Technologies Inc.

\section{Ozone Disinfection}

The pilot plant, engineered in association with Ozonia North America Ltd., consisted of two stainless steel columns, each $5.8 \mathrm{~m}$ high and $0.15 \mathrm{~m}$ diameter. Only the first column was used for ozone diffusion in the present study. Ceramic diffusers supplied ozone generated from a liquid oxygen source, at a gas flow rate of $0.35 \mathrm{~m}^{3} / \mathrm{h}$ and $\mathrm{O}_{3}$ concentrations of 0.5 to $2.3 \%$ by weight in oxygen, depending on the electrical current setting of the ozone generator (Ozonia, Model LN 103). The countercurrent liquid flow rate was $0.5 \mathrm{~m}^{3} / \mathrm{h}$ at a temperature of $21^{\circ} \mathrm{C}$. In the latter part of this study, two internally mixed and interconnected equalization tanks of $4 \mathrm{~m}^{3}$ total capacity were used upstream of the pilot plant to smooth out COD and other variations in the quality of the MUCWTP effluent and to assist with the interpretation of ozonation performance.

The ozone concentrations in the influent gas and off-gas were measured by UV absorbance monitors (Griffin, EG-2001-HC), and residual $\mathrm{O}_{3}$ was measured at various points in the columns by the indigo trisulfonate method (Gordon et al. 1987). Before each set of tests and at the end of each day of sampling, the pilot plant was flushed with water to prevent buildup of biological films.

Fecal coliforms (FC) were used as indicators to measure disinfection performance. The following parameters were measured according to Standard Methods (APHA et al, 1989) to assist and predict ozone disinfection performance: $\mathrm{COD}, \mathrm{BOD}_{5}, \mathrm{SS}, \mathrm{TOC}, \mathrm{ORP}, \mathrm{DO}$, temperature, $\mathrm{pH}$ and turbidity. Other parameters were measured occasionally, such as $\mathrm{H}_{2} \mathrm{~S}, \mathrm{NH}_{3}, \mathrm{NO}_{2}-\mathrm{NO}_{3}$ and colour.

\section{Biofilm Growth in the Tunnel}

Seven sets of samples of the effluent from the MUCWTP were taken during the summer of 1993 at the entrance and exit of the outfall. A suitable lag period was incorporated to account for the travel time in the tunnel. Parameters analysed included COD, dissolved oxygen, phosphorus (reactive and total), suspended solids (SS), turbidity, fecal coliforms and enterococci. All measurements followed standard procedures (APHA et al. 1989), and were performed in triplicate.

\section{Dilution in the River}

A previous study in the fall of 1983, conducted before construction of the MUCWTP had been completed, had given minimum dilution ratios of 
$\sim 75$, based on effluent flows of $\sim 14 \mathrm{~m}^{3} / \mathrm{s}$ and using a conservative tracer (Boulanger 1984). The aim of the present study was to investigate effective dilutions, based on microbial counts and phosphorus concentrations (considered equivalent to a conservative tracer).

The river was sampled on four occasions during the summer of 1993. Sampling points included the effluent channel at the MUCWTP, the outfall exit structure immediately before discharge into the river, $0.5 \mathrm{~km}$ upstream from the discharge, directly downstream from the discharge, and $2.5 \mathrm{~km}$ and $4 \mathrm{~km}$ downstream. The last point was close to the beach at ile Evers, since this location was identified as the critical point for microbial levels. The plume was sampled at three depths, as well as at three cross-sectional positions in order to best locate the plume centreline. Sampling in the river was time-lagged to be consistent with the velocity of flow. Parameters analysed were the same as those for the outfall tunnel.

At the time of the study, small discharges of raw domestic sewage were still occurring directly into the river upstream from the outfall; these would affect the phosphorus concentrations and microbial counts. Near the western tip of the Island of Montreal, at the location of the water treatment plant intake, phosphorus and microbial levels were negligible, and it is assumed that such will be the case downstream once all raw sewage discharges have ceased. The following strategy was followed to account for the upstream contributions. Phosphorus concentrations measured immediately upstream of the outfall were subtracted from all downstream values, For the two colder samples measured in June, it was assumed that die-off of the upstream microbes had occurred by the time the plume had reached île Evers, and therefore, no correction was made. For the warmer samples in July and August, the upstream microbial concentrations were subtracted from those measured downstream. This behaviour was supported by on-site observations (see below).

\section{Results}

\section{Effluent Quality from the MUCWTP}

The effluent quality from the MUCWTP varies widely with season, with especially high coliform levels during the summer months. Since the objective of the physicochemical treatment process is to remove phosphorus (producing effluent levels consistently below $1 \mathrm{mg} / \mathrm{L}$ and frequently below $0.3 \mathrm{mg} / \mathrm{L}$ ), the values of other parameters are considerably higher than would be expected from a biologically treated effluent, as shown in Table 1.

\section{UV Disinfection}

Fig. 1 shows the results of typical multi-intensity/multi-flow experiments, conducted over 30-minute periods, during which the influent quality was reasonably constant. Dose is a product of intensity and expo- 
Table 1. Characteristics of MUCWTP effluent during the study

\begin{tabular}{lll}
\hline \hline Parameter & Range & Median \\
\hline COD $(\mathrm{mg} / \mathrm{L})$ & $40-170$ & 99 \\
$\mathrm{TOC}(\mathrm{mg} / \mathrm{L})$ & $10-40$ & 25 \\
$\mathrm{BOD}_{5}(\mathrm{mg} / \mathrm{L})$ & $26-48$ & 33 \\
$\mathrm{SS}(\mathrm{mg} / \mathrm{L})$ & $15-20$ & - \\
Iron in solids $(\%)$ & $3.7-13.6$ & - \\
Turbidity (NTU) & $6-15$ & 10 \\
UV $_{254}$ transmittance $(\%)$ & $31-69$ & 45 \\
Fecal coliforms (CFU / $100 \mathrm{~mL})$ & $0.4-4$ million & 1.6 million \\
\hline
\end{tabular}

sure time, and the fact that all points for $\mathrm{FeCl}_{3}$ lie on a smooth curve suggests an absence of changing hydraulic behaviour over the different combinations of intensities and flow rates. The change in slope (at a dose of approximately $25 \mathrm{~mW} \cdot \mathrm{s} / \mathrm{cm}^{2}$ ) marks the transition between inactivation of free microbes or microbes associated with small particles, and microbes associated with larger particles.

The use of alum as a coagulant had several beneficial effects for this study, as may be seen in Fig. 1. FC concentrations decreased by about 0.5 log-units prior to UV disinfection (zero dose) when $5 \mathrm{mg} \mathrm{Al}^{3+} / \mathrm{L}$ was used instead of $8.4 \mathrm{mg} \mathrm{Fe}^{3+} / \mathrm{L}$. Alum also had the effect of improving overall wastewater quality, especially UV transmittance and turbidity, yielding more effective use of the applied doses. Finally, it is possible that the particulates formed from alum flocs are more effectively penetrated by UV

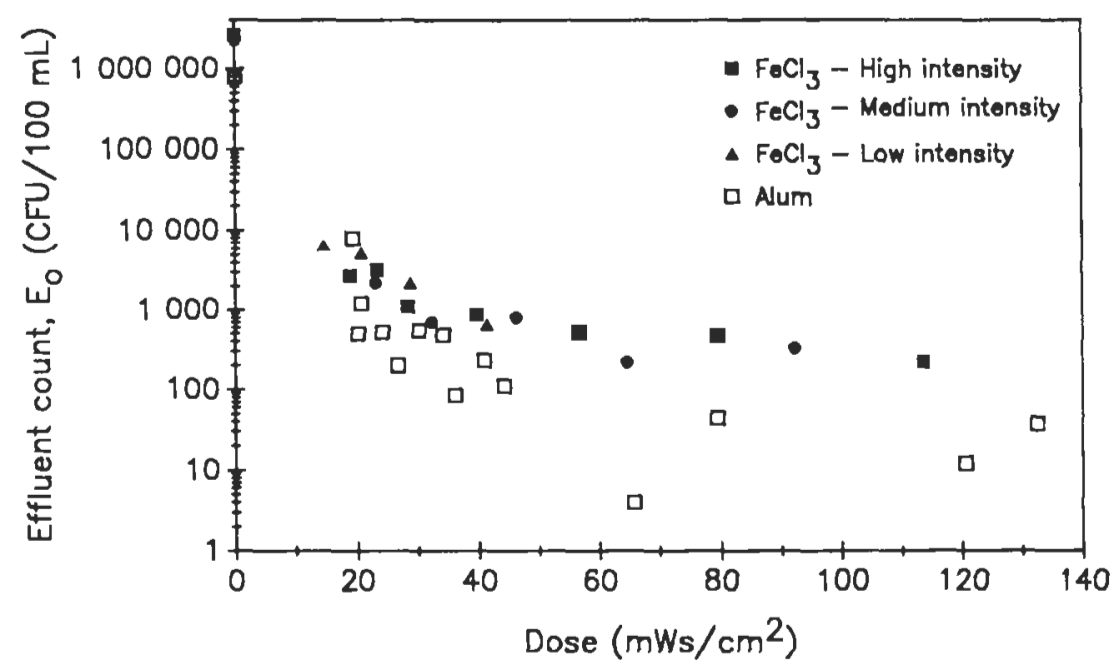

Fig. 1. Typical dose-response results for UV disinfection. 
light than the corresponding iron flocs, because the very low FC counts at doses above $50 \mathrm{~mW} \cdot \mathrm{s} / \mathrm{cm}^{2}$ imply that the particulate-associated microorganisms are also inactivated.

Reactivation effects (i.e., dark repair and photoreactivation) were studied with a view to establishing two criteria: (i) the maximum photoreactivation and dark repair potentials for various doses and coagulants used, and (ii) the anticipated overall repair in the river, which would be depth-dependent for photoreactivation only. Seasonal and time-of-day effects were not studied in detail.

To evaluate the amount of damaged bacteria that were repaired after disinfection, an overall maximum repair ratio $(\eta)$ can be defined as follows:

$$
\eta=\frac{E_{p m}-E_{o}}{N_{o}-E_{o}} \approx \frac{E_{p m}}{N_{o}}
$$

where $\mathrm{E}_{\mathrm{pm}}$ is the maximum photoreactivated plus dark repaired effluent count within the set of bottles (CFU / $100 \mathrm{~mL}$ ); $\mathrm{E}_{\mathrm{o}}$ is the effluent count prior to reactivation (CFU/100 mL); $\mathrm{N}_{\mathrm{o}}$ is the influent count (CFU/100 mL); $\mathrm{N}_{\mathrm{o}}$ $\mathrm{E}_{\mathrm{o}}$ represents the organisms which had been damaged, some of which could be repaired by dark or photo-induced repair processes; and $\eta$ is the ratio of damaged microorganisms that were able to repair by photoreactivation and dark repair processes.

Under reactivating conditions, $E_{o}$ would be small compared to $E_{p m}$ and $N_{o}$ and hence, it can be neglected. A large value of $\eta$ would indicate that a large number of damaged bacteria was able to repair. Maximum repair would occur close to the water surface.

A ratio which accounts for repair due to photoreactivation only, $\eta_{p}$, can be expressed as follows:

$$
\eta_{p}=\frac{E_{p m}-E_{d r}}{N_{o}-E_{o}} \approx \frac{E_{p m}-E_{d r}}{N_{o}}
$$

where $E_{d r}$ is the count after dark repair only (CFU/100 mL).

Finally, a ratio which accounts for dark repair processes only, $\eta_{\mathrm{dr}}$, is given as:

$$
\eta_{d r}=\frac{E_{d r}-E_{o}}{N_{o}-E_{o}} \approx \frac{E_{d r}-E_{o}}{N_{o}}
$$

Table 2 shows typical sets of repair data when ferric chloride or alum coagulants were used. Sample bottles were slightly submerged in the effluent channel and exposed to sunlight for $2 \frac{1}{2}$ hours. The repair ratios ( $\eta$, etc.) tended to increase with decreasing UV dose, i.e., the repair process was minimized at higher doses and tended to be lower for the alum effluents. This is in agreement with results published by Lindenauer and Darby (1993), but contrary to claims made in the EPA manual (EPA 1986) 
Table 2. Photoreactivation experiments

\begin{tabular}{cccccccc}
\hline \hline $\begin{array}{c}\text { Coagulant } \\
\text { and initial } \\
\text { count } \\
\left(\mathrm{N}_{\mathrm{o}}\right)\end{array}$ & Dose & $\begin{array}{c}\text { Effluent } \\
\text { count prior } \\
\text { to photo- } \\
\text { reactivation } \\
\left(\mathrm{E}_{\mathrm{o}}\right)\end{array}$ & $\begin{array}{c}\text { Dark } \\
\text { repair } \\
\text { count } \\
\left(\mathrm{E}_{\mathrm{dr}}\right)\end{array}$ & $\begin{array}{c}\text { Max } \\
\text { photo- } \\
\text { reactivated } \\
\text { effl. count } \\
\left(\mathrm{E}_{\mathrm{pm}}\right)\end{array}$ & $\eta$ & $\eta_{\mathrm{p}}$ & $\eta_{\mathrm{dr}}$ \\
\hline $\mathrm{FeCl}_{3}$ & High & 20 & 3,500 & 30,000 & 0.013 & 0.011 & 0.001 \\
$2,400,000$ & Medium & 3,200 & 8,400 & 74,000 & 0.031 & 0.027 & 0.002 \\
& Low & 10,000 & 180,000 & 250,000 & 0.104 & 0.029 & 0.071 \\
& Hlum & 10 & 1,400 & 1,700 & 0.002 & 0.0003 & 0.00017 \\
840,000 & Medium & 91 & 1,000 & 16,000 & 0.019 & 0.018 & 0.001 \\
& Low & 300 & 17,000 & 67,000 & 0.080 & 0.060 & 0.019 \\
\hline
\end{tabular}

aAll counts in units of CFU $/ 100 \mathrm{~mL}$.

and by Whitby and Palmateer (1993), who stated that no correlation exists between original dose and ratio of photorepaired to non-photorepaired coliforms.

To simulate the effects of dark repair in the outfall tunnel followed by photoreactivation in the river, bottles containing UV-inactivated samples were wrapped and suspended at various depths in the effluent channel for $2 \frac{1}{2}$ hours, then unwrapped and exposed at the same depths for a further $2 / 2$ hours. The results are plotted in Fig. 2. It is apparent that dark

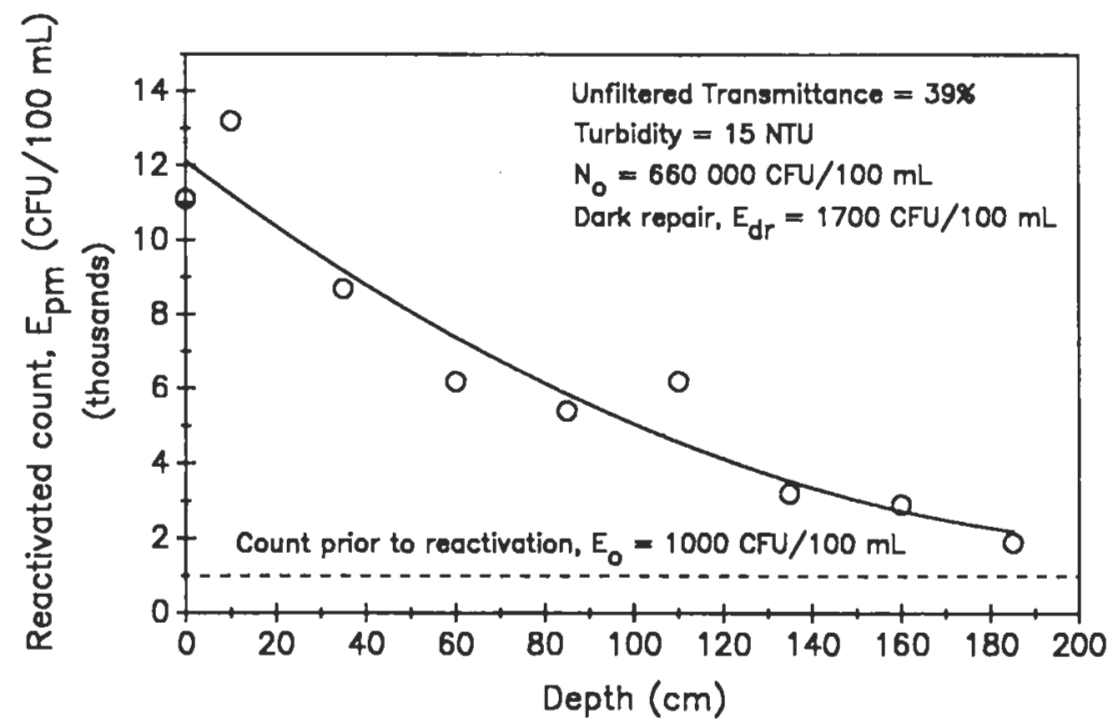

Fig. 2. Depth effects on photoreactivation. 
repair only is reached at a depth exceeding $1.85 \mathrm{~m}$ (say $2 \mathrm{~m}$ ), and that a $50 \%$ reduction in photorepair had occurred by a depth of approximately $0.5 \mathrm{~m}$. A maximum photorepair increase $\left(\mathrm{E}_{\mathrm{pm}} / \mathrm{E}_{\mathrm{o}}\right)$ of approximately $1 \mathrm{log}$ unit was observed.

\section{Ozone Disinfection}

Step input tracer studies indicated an average detention time of 12.3 min in the first column, with a relatively high dispersion number, $\mathrm{D} / \mathrm{ul}$, of 0.124 (where $D$ is the dispersion coefficient, $u$ the linear velocity and 1 the length). An examination of ozone profiles in the pilot plant column showed that the reactor exhibited plug flow over its intermediate $4 \mathrm{~m}$ length; however, at the top and bottom the introduction and evacuation of liquid lead to a relatively large degree of mixing.

Experiments were conducted with $\mathrm{FeCl}_{3}$-treated wastewater from the beginning of July until mid-October 1992. The average temperature of the

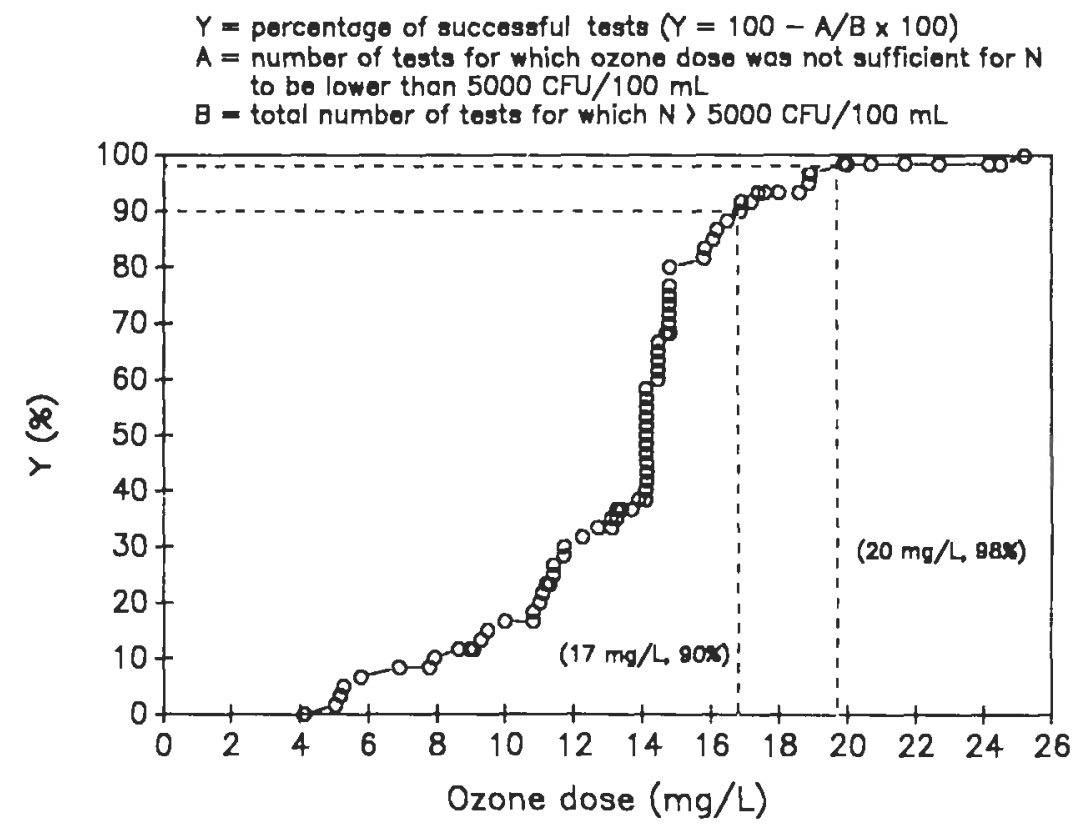

Fig. 3. Probability plot for ozone disinfection.

wastewater was approximately $21^{\circ} \mathrm{C}$. Most tests were performed between $14 \mathrm{~h} 00$ and $22 \mathrm{~h} 00$. There was a lack of correlation between ozone dose and FC survival count (N) immediately following ozonation. This is due to variability of the characteristics of the wastewater and especially the occasional presence of $\mathrm{H}_{2} \mathrm{~S}$. A probability plot based on tests with $\mathrm{N}$ higher than the target 5,000 CFU $/ 100 \mathrm{~mL}$ (60 out of 178 tests) is shown in Fig. 3 . This figure shows that an ozone dose of $17 \mathrm{mg} / \mathrm{L}$ reduced the number of cases for which $\mathrm{N}$ was higher than the target level to $10 \%$. A dose of 20 
$\mathrm{mg} / \mathrm{L}$ reduced this number to $2 \%$. It should be noted that these are the applied dosages; ozone transfer efficiency (OTE) based on off-gas measurements varied between 90 and $99 \%$ depending on the COD and the ozone dose. OTE increased with higher COD. Samples taken from the second column generally yielded higher FC concentrations. This is presumably due to sloughed biofilms, favourable growth conditions resulting from supersaturated dissolved oxygen levels $(35-40 \mathrm{mg} / \mathrm{L})$ and the low velocity and Reynolds number (respectively, $0.46 \mathrm{~m} / \mathrm{min}$ and 1,160), and from the fact that the pilot plant was not operated continuously.

Ozone residuals at different points in the pilot plant were measured in order to calculate an integrated CT value (where $C$ and $T$ were residual concentrations and detention times at various points along the length of the first column, respectively) and to ascertain the persistence of ozone in the wastewater. The integrated CT value measures the exposure of the wastewater to the ozone from the inlet at the top of the column to the sampling point at the base. Results are shown in Fig. 4. They demon-

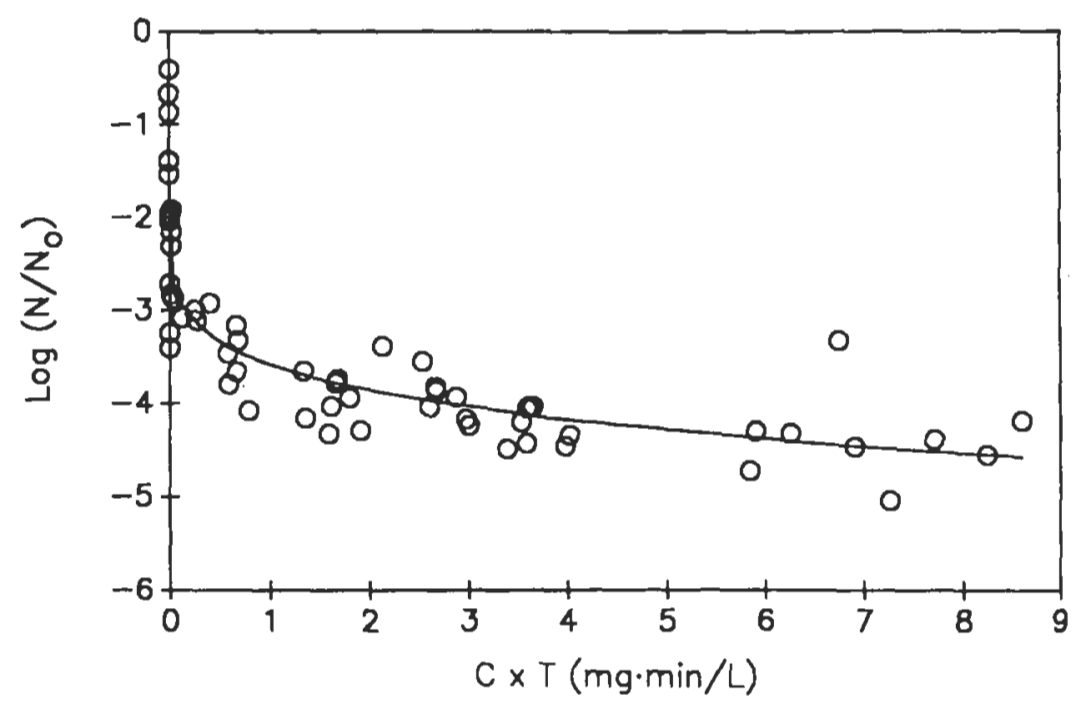

Fig. 4. Survival versus integrated CT values.

strate that for a FC survival ratio $\left(\mathrm{N} / \mathrm{N}_{0}\right)$ of $3.1 \times 10^{-3}$ (required to reach the target FC level), a CT value of approximately $0.4 \mathrm{mg} / \mathrm{min} / \mathrm{L}$ is needed. For a $\mathrm{N} / \mathrm{N}_{0}$ reduction of $4 \mathrm{log}$ units or greater, $\mathrm{CT}$ values of 2.3 and 2.9 $\mathrm{mg} \cdot \mathrm{min} / \mathrm{L}$ were required for 90 and $98 \%$ of the cases tested, respectively.

Equalization tanks were employed to yield constant COD levels for a study comparing wastewaters coagulated by $\mathrm{FeCl}_{3}$ or alum (March 1993, wastewater temperature $9^{\circ} \mathrm{C}$ ). Results indicated that ozone disinfection efficiency was increased when alum was used, as shown in Fig. 5. It is seen that to reach the target level of $5,000 \mathrm{CFU} / 100 \mathrm{~mL}$ in the effluent (requir- 
- March 3 - Alum, $\mathrm{N}_{\mathrm{o}}=270000 \mathrm{CFU} / 100 \mathrm{~mL}$

- March $10-\mathrm{FeCl}_{3}, \mathrm{~N}_{0}=430000 \mathrm{CFU} / 100 \mathrm{~mL}$

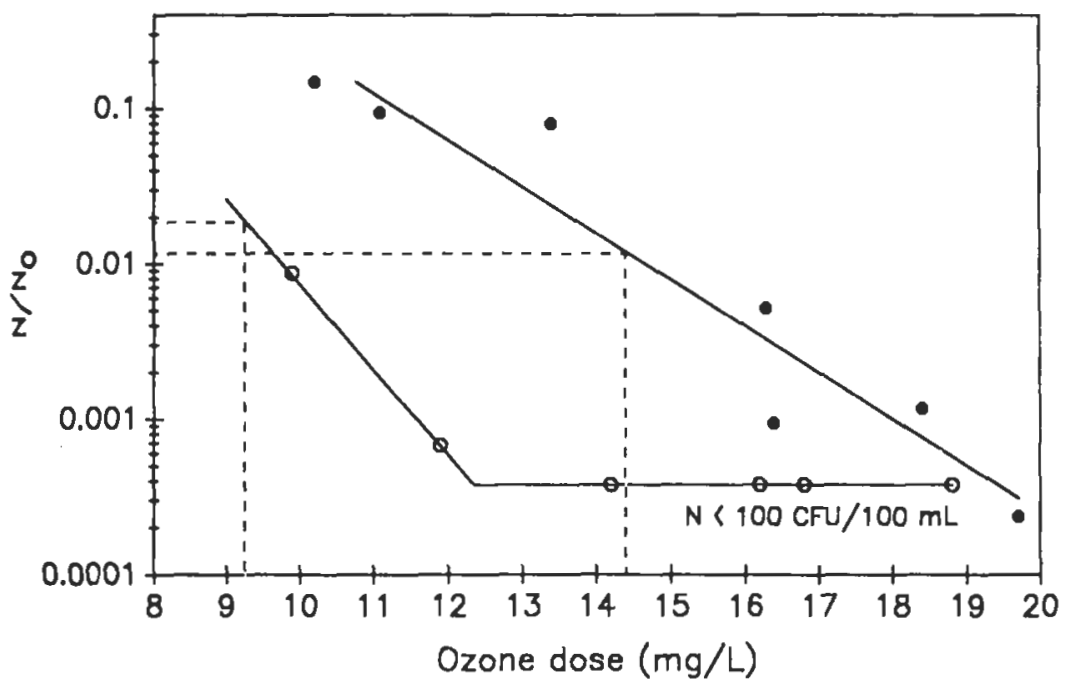

Fig. 5. Comparison of ozone disinfection following $\mathrm{FeCl}_{3}$ or alum coagulation.

ing $\mathrm{N} / \mathrm{N}_{0}$ of 0.0116 and 0.0185 for $\mathrm{FeCl}_{3}$ and alum, respectively), a $35 \%$ reduction in the required ozone dose was observed when using alum.

\section{Downstream Effects}

In order to calculate the allowable FC concentration immediately after UV inactivation, the two scale-up factors to be considered are overall reactivation (microbial repair) and effective dilution in the river (which would include actual dilution, regrowth, dieoff, scavenging and sedimentation). Biofilm growth in the tunnel might also have to be taken into account.

\section{Repair after UV treatment}

To simplify the calculation of overall average repair over depth, it is necessary to assume complete vertical mixing, dark repair over the entire depth of the river $(12 \mathrm{~m})$, and an integration of the decreasing photo-reactivation effect over the depth $0-2 \mathrm{~m}$. If Fig. 2 can be considered typical, the dark repair fraction is approximately

$$
\frac{E_{d r}}{E_{o}}=\frac{1,700}{1,000}=1.7
$$

and by graphical integration, the average photorepair over $2 \mathrm{~m}$ is approximately 


$$
\left(\frac{E_{p m}-E_{d r}}{2}\right)+E_{o}=\left(\frac{14,000-1,700}{2}\right)+1,000=6.15
$$

Thus, at this dose, $\left(50 \mathrm{~mW} \cdot \mathrm{s} / \mathrm{cm}^{2}\right)$, the overall reactivation ratio is the sum of dark repair over the entire depth, plus average photorepair over $2 \mathrm{~m}$, or

$$
1.7+\left(\frac{6.15 \times 2}{12}\right)=2.73
$$

Clearly, this calculation would have to be repeated over a range of doses, as the extent of reactivation depends on the UV dose (as shown in Table 2). It should also be noted that according to one study, photoreactivation must take place within 3 hours of disinfection (Kelner 1949), and in another report, photoreactivation was not measured in a stream after fullscale UV disinfection (Whitby and Palmateer 1993). Thus the impact of photoreactivation for the present situation might be negligible.

\section{Biofilm growth in the tunnel}

Results are shown in Fig. 6 and 7 for enterococci and SS, respectively. Fecal coliforms and turbidity followed similar trends. Without biofilm growth and sloughing phenomena, one would have expected, on average, that the curves for the inlet and outlet would coincide. Although Fig. 6 and 7 do not show major differences between the two curves (taking into



Fig. 6. Enterococci counts measured at tunnel inlet and outlet. 


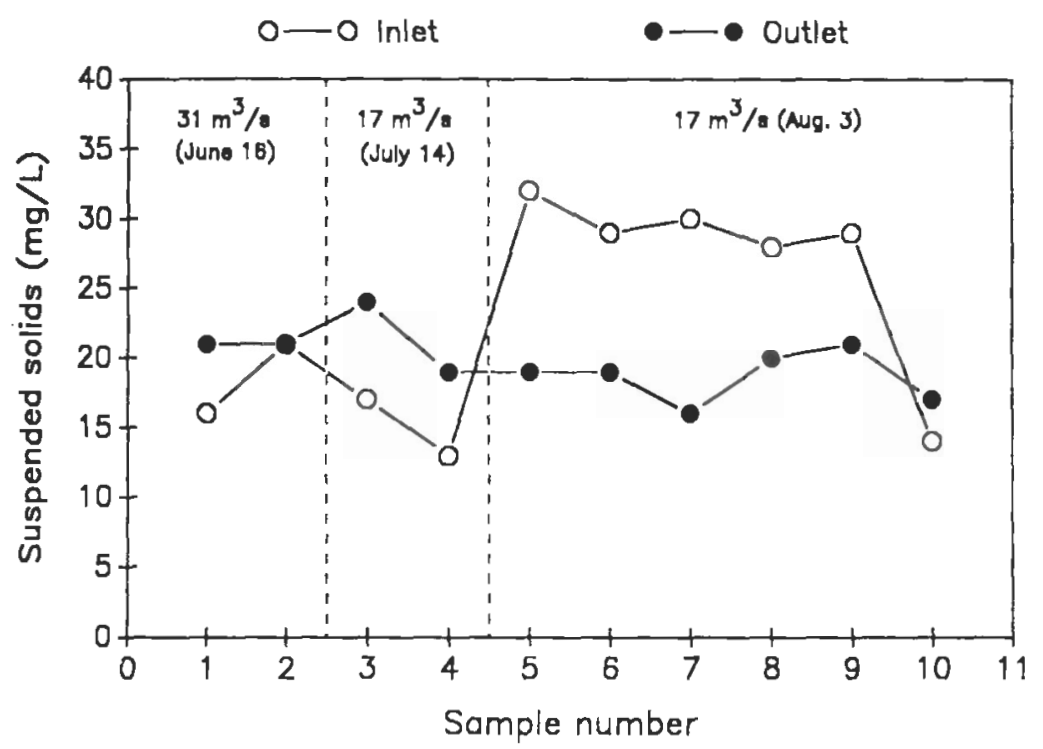

Fig. 7. Suspended solids concentrations measured at tunnel inlet and outlet.

account errors in the measurements, especially with SS), there are instances where the outlet concentrations are higher than the inlet; see, for example, sample numbers 1-4 in Fig. 7. The likely explanation regarding why in some cases the outlet SS values should be higher, whereas in others the inlet is higher, is that there is intermittent sloughing of a biofilm. Cell replication in the liquid phase is unlikely due to the low nutrient level. In practice, the effect wouid be that the levels of enterococci (or other microbes) measured downstream of the outfall might on occasion be considerably higher than would be expected based on measurements of effluent quality immediately following disinfection.

\section{Dilution in the river}

Fig. 8 shows dilution factors measured for fecal coliforms, enterococci and phosphorus on the four sampling dates at the $4-\mathrm{km}$-downstream location. These factors were calculated as the ratio of the values measured at the outfall structure, to the highest values measured at the 4 $\mathrm{km}$ downstream point. If phosphorus can be considered to be a conservative tracer, then the hydraulic dilution would appear to be between 13 and 21, and not 75 as reported in 1984. It is also evident from Fig. 8 that the effective dilution factors for the microorganisms (which would include die-off, reactivation and other non-conservative behaviour) decrease as river temperature increases, and these factors eventually approach that of phosphorus. Fecal coliform dilution factors were, in fact, 17.6 in July and 32.7 in August. The enterococci appear to be more sensitive to low temperatures. Contributions from external sources, such as 
sediments, runoff and upstream, could alter the value of the dilution factor as calculated, but the fact that the three parameters yield similar values for July and August indicates that a realistic dilution factor might be taken as 20 .

Thus, to calculate the value of the overall scale-up fraction, one would divide the overall reactivation ratio by the dilution factor. For the present study, this would yield (using 20 as a reasonable worst case):

$$
\frac{1}{20} \times(2.73)=0.136
$$

for UV disinfection, and 0.05 for the ozone case (assuming no dark repair). If the target level at île Evers is $200 \mathrm{CFU} / 100 \mathrm{~mL}$, then neglecting background values, this would require a count immediately following UV disinfection of $200 / 0.136=1,470 \mathrm{CFU} / 100 \mathrm{~mL}$, and $200 / 0.05=4,000$ $\mathrm{CFU} / 100 \mathrm{~mL}$ following ozonation. This latter value is very close to the value of 5,000 suggested by Payette (1992). Note, though, that from Fig. 1 , an effluent count of $1,470 \mathrm{CFU} / 100 \mathrm{~mL}$ with $\mathrm{FeCl}_{3}$ coagulation and an $\mathrm{N}_{\mathrm{o}}$ of $10^{6}$ requires a UV dose of approximately $25 \mathrm{~mW}-\mathrm{s} / \mathrm{cm}^{2}$. Therefore, the dose-dependent photoreactivation fraction which was calculated above (i.e., 2.73) may have to be reassessed and a slightly higher value used. Furthermore, Fig. 1 is given as a typical representation of UV disinfection performance: it is not meant as the definitive design curve for the MUCWTP.

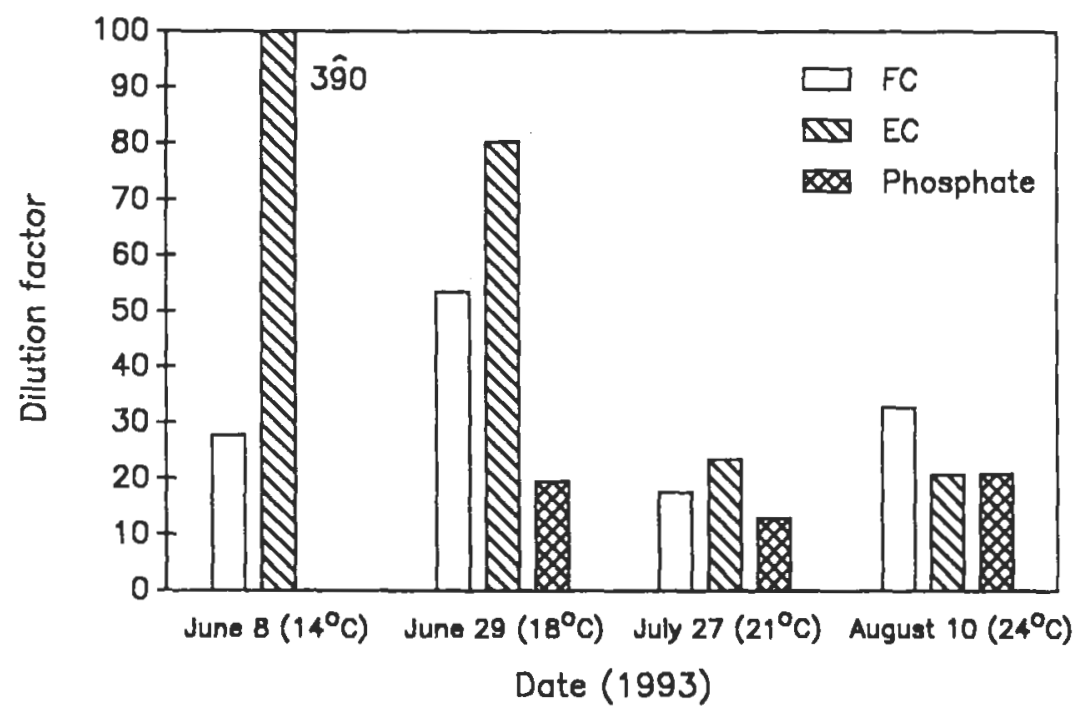

Fig. 8. Dilution factors for fecal coliforms, enterococci and phosphorus. 


\section{Discussion and Implications of UV and Ozone Disinfection}

The implications of using the alternative disinfection processes may be discussed under two broad categories: needs for upstream process modifications and effects on the receiving water body. For both UV and ozonation, the use of alum as the coagulant chemical yielded significant improvements in disinfection performance. In the case of UV, this is believed to be due to the lower turbidity, higher UV transmissivity and lower content of iron in the particulates (iron is known to absorb UV light [Darby et al. 1993]). For ozone, it is thought that iron acts as a scavenger for the free radicals which are produced during ozonation, and which are responsible for much of the disinfection action. Interestingly, the use of alum did not improve COD removal. COD as well as other reduced substances are major consumers of ozone and, especially in the present study, they create an ozone demand which could be of the same order as that needed for disinfection alone. Another important improvement in upstream process performance, apart from the COD removal already mentioned in the case of ozonation, would be regarding particulate removal, especially in the case of UV disinfection.

In terms of impact on the receiving water body, it should be mentioned that during both studies, tests revealed no increased toxicity (daphnia, Microtox and Ames procedures) due to the respective disinfection processes. Photoreactivation in the river of inactivated organisms is a concern, but its overall effect may well be balanced by sedimentation, scavenging, natural die-off, and the relatively shallow depth of light penetration compared to the overall depth of the river. On the other hand, although the ozone residual itself clearly would not survive for the entire retention period of the outfall tumel, ozonation does increase the dissolved oxygen (since the efficiency of conversion of oxygen to ozone is $\sim 10 \%$ ) and can render recalcitrant organic molecules more biodegradable, as evidenced by increases in BOD levels in many effluent samples. Thus the possibility of biofilm formation on the wall of the outfall tunnel, leading to the regrowth of coliforms and other organisms, is rather strong.

\section{Conclusions}

Both UV and ozone disinfection were capable of meeting the disinfection criteria for the physicochemical effluent from the wastewater treatment plant of the Montreal Urban Community. Doses of approximately 25 $\mathrm{mW} \cdot \mathrm{s} / \mathrm{cm}^{2}$ for $\mathrm{UV}$ or $17 \mathrm{mg} / \mathrm{L}$ for ozone would be required under the current operating conditions ( $\mathrm{FeCl}_{3}$ as coagulant). Both processes would be enhanced by improvements in upstream treatment, especially the replacement of ferric chloride by alum. Effluents following UV disinfection may show a slight bacterial regrowth by both dark and photo-repair mechanisms, and would not contain residuals to prevent biofilm growth in the outfall tunnel. The ozonated effluent would be rich in dissolved oxygen 
and may have an increased BOD, thus further increasing the chances of biofilm growth in the outfall tunnel; hence an overall compromise in disinfection performance. Effective scale-up factors for UV disinfection, being the ratio of microbial counts immediately following disinfection to the target levels at île Evers, were calculated as a worst case to be as low as 7.35 (i.e., $0.136^{-1}$ ) if photoreactivation were included, and 20 if not. The value for ozone disinfection would be 20 . This is slightly lower than the value of 25 which is being considered by the MEF.

\section{Acknowledgments}

We wish to acknowledge the following students and colleagues who contributed greatly to the disinfection research: Fadi Absi, William Cairns, Christian Comair, Jennifer Finkenbine, François Gamache, Pierre Liechti, Chaim Motzen, Kim Nishimura and Gail Sakamoto. The staff at the MUCWTP as well as Eva Waldron in the Environmental Engineering Laboratories at McGill University were of invaluable assistance. Finally, the support of the Quebec Ministry of the Environment and Fauna, Trojan Technologies Inc., Ozonia, and Canadian Liquid Air is gratefully acknowledged.

\section{References}

APHA, AWWA and WPCF. 1989. Standard methods for the examination of water and wastewater, 17th edition. American Public Health Association, Washington, D.C.

Boulanger, F. 1984. Station d'épuration de la CUM. Répercussions environnementales d'un déversement d'eaux usées prétraitées à l'émissaire de l'île aux Vaches. Rapport d'étude. LHL-901.

Bryers, J.D. 1987. Biologically active surfaces: Processes governing the formation and persistence of biofilms. Biotech. Prog. 3:57-68.

Cairns, W.L. 1993. Comparing disinfection by ultraviolet light and chlorination - the implications of mechanism for practice, p. 555-566. Proc. Planning, Design and Operations of Effluent Disinfection Systems, Water Env. Fed., Whippany, N.J.

Chen, C., R. Nur, J.F. Stahl, R.W. Horvath and J.F. Kuo. 1993. UV inactivation of bacteria and viruses in tertiary treatment, p. 61-72. Proc. Planning, Design and Operations of Effluent Disinfection Systems, Water Env. Fed., Whippany, N.J.

Darby, J.L., K.E. Snider and G. Tchobanoglous. 1993. Ultraviolet disinfection for wastewater reclamation and reuse subject to restrictive standards. Wat. Env. Res. 65:169-180.

EPA. 1991. Municipal wastewater disinfection. Protecting aquatic life and human health from the impacts of chlorination. February.

EPA. 1986. Municipal wastewater disinfection. Design manual. EPA/625/186/021, U.S. Environmental Protection Agency, Cincinnati.

Gehr, R. and W.L. Cairns. 1994. UV disinfection for large-scale and/or low 
quality wastewater treatment comes of age, p. 327-329. Proc. 10th Eastern Region Conference, Canadian Association on Water Quality. Montreal, Quebec, November 15 and 16.

Gehr, R., J. Finkenbine and K. Nishimura. 1994. L'effluent de la station d'épuration de la CUM : L'effet de l'emmissaire et de la dilution dans le fleuve. Rapport final. Université McGill, Département de génie civil.

Gordon, G., W.J. Cooper, R.G. Rice and G.E. Pacey. 1987. Disinfectant residual measurement methods. American Water Works Association, Washington D.C.

Hamel, S. 1993. Personal communication, Chief, Office of Technical Evaluations, Urban Abatement Directorate, Quebec Ministry of the Environment and Fauna.

Jacangelo, J.G., N.L. Patania, K.M. Reagan, E.M. Aieta, S.W. Krasner and M.J. McGuire. 1989. Ozonation: assessing its role in the formation and control of disinfection by-products. J. Amer. Water Works Assn. 81:74-84.

Kelner, A. 1949. Photoreactivation of ultraviolet-irradiated Escherichia coli, with special reference to the dose-reduction principle and to ultraviolet-induced mutation. J. Bacteriol. 58:511-522.

Levallois, P. 990. Les risques pour la santé reliés aux polluants chimiques présents dans l'eau potable. Département de la santé communautaire du Centre hospitalier de l'Université Laval.

Lindenauer, K.G. and Darby, J.L. 1993. Evaluation of ultraviolet light disinfection: Significance of photoreactivation, p. 49-59. Proc. Planning, Design and Operations of Effluent Disinfection Systems, Water Env. Fed., Whippany, N.J.

Lund, V. and Ormerod, K. 1995. The influence of disinfection processes on biofilm formation in water distribution systems. Water Res. 29:1013-1021.

Maarschalkerweerd, J., R. Murphy and G. Sakamoto. 1990. Ultraviolet disinfection in municipal wastewater treatment plants. Wat. Sci. Technol. 22:145-152.

Miltner, R.J., H.M. Shukairy and R.S. Summers. 1992. Disinfection by-product formation and control by ozonation and biotreatment. J. Amer. Water Works Assn. 84:53-62.

Payette, F. 1992. MEF, Direction de l'assainissement urbain. Letter to Paul Goulet, Conseiller au directeur, Service de l'Environnement, Communauté urbaine de Montréal.

Picologlou, B.F., N. Zelver and W.G. Characklis. 1980. Biofilm growth and hydraulic performance. J. Hydraul. Div, Amer. Soc. Civil Engin. 106:733-746.

Van Leeuwen, H.J. 1987. Preliminary investigation into the improvement of the biodegradability of organic substances in surface waters and effluents through ozonation. Wat. Sci. Technol. 19:931-937.

Whitby, G.E. and G. Palmateer. 1993. The effect of UV transmission, suspended solids, wastewater mixtures and photoreactivation on microorganisms in wastewater treated with UV light. Wat. Sci. Technol. 27:379-386.

White, G.C. 1986. Handbook of chlorination, 2nd ed. Van Nostrand Reinhold, New York.

White, S.C., E.B. Jernigan and A.D. Venosa. 1986. A study of operational ultraviolet equipment at secondary treatment plants. J. Water Pollut. Control. Fed. 58:181-192. 